\title{
Pengaruh Pesan Iklan Televisi "Dana App-Dompet Digital Indonesia 60s (2018)" terhadap Keputusan Penggunaan Aplikasi \\ Dana
}

\author{
Valencia, Ahmad Junaidi \\ valencia.915160078@stu.untar.ac.id,ahmadd@fikom.untar.ac.id \\ Fakultas Ilmu Komunikasi Universitas Tarumanagara
}

\begin{abstract}
This research attempts to adopt the effect of television advertisement to decision of using digital wallet application. This study is entitled "The effect of Television Advertising Message "Dana App - Dompet Digital Indonesia 60s (2018)" to Decision of using Dana Application. This Study aims to determine of how The effect of Advertising Message "Dana App-Dompet Digital Indonesia 60s (2018)" to Decision of using Dana Application on millennials generation in DKI Jakarta. This study used a quantitative research survey method and the primary data which the primary data was obtained directly from respondents through questionnaires using google form. Research data were obtained from questionnaires, library studies, journals and online data. The used sample uses 100 male or female respondents, who is Millennials Generation in DKI Jakarta, aged between 18-37years old, and has been watched television advertising "Dana App - Dompet Digital Indonesia 60s (2018)" chosen by purposive sampling. The data results were analyzed by using simple linear regression analysis technique. The results of this study can be concluded that message of "Dana App-Dompet Digital Indonesia 60s (2018)" has significant influences with Decision of using Dana Application in DKI Jakarta for 30,3\%. Based on the results of T-Test testing,variable (X) advertising message (message content, message structure, message format, and message source) is which means $H_{0}$ was rejected and Ha was accepted, with sig $<\alpha$ is $0,000<0,05$, The results of this study can be concluded that message of "Dana App-Dompet Digital Indonesia 60s (2018)" has significant influences with Decision of using Dana Application
\end{abstract}

Keywords: advertising message, television advertising, using dana application.

\begin{abstract}
Abstrak
Penelitian ini mengangkat tentang pengaruh iklan televisi terhadap keputusan penggunaan aplikasi dompet digital. Penelitian ini berjudul "Pengaruh Pesan Iklan Televisi "Dana App Dompet Digital Indonesia 60s (2018)" Terhadap Keputusan Penggunaan Aplikasi Dana. Penelitian ini bertujuan untuk Ingin mengetahui bagaimana pengaruh iklan televisi aplikasi Dana "Dana App - Dompet Digital Indonesia 60s (2018)" terhadap keputusan penggunaan Aplikasi Dana pada generasi Milenial di DKI Jakarta. Penelitian ini merupakan penelitian kuantitatif dengan pendekatan survey dan menggunakan data primer yang diperoleh secara langsung dari responden melalui kuesioner menggunakan google form. Data penelitian diperoleh dari kuesioner, studi pustaka, jurnal, dan data online. Teknik pengambilan sampel menggunakan Purposive Sampling dengan sampel pria atau wanita sebanyak 100 responden, yang merupakan generasi milenial di DKI Jakarta, yang berumur antara 18-37 tahun, dan pernah menonton iklan televisi "Dana App - Dompet Digital Indonesia 60s (2018)". Teknik analisis yang digunakan adalah analisis regresi linear sederhana. Hasil penelitian ini dapat disimpulkan bahwa Pesan Iklan "Dana App - Dompet Digital Indonesia 60s (2018)" berpengaruh signifikan terhadap keputusan penggunaan Aplikasi Dana di DKI Jakarta sebesar 30,3\%. Pengujian Uji T pada variabel (X) pesan iklan (isi pesan, struktur pesan, format pesan,
\end{abstract}


dan sumber pesan) adalah $\mathrm{H}_{0}$ ditolak dan Ha diterima, dengan Nilai sig $<\alpha$ yaitu $0,000<0,05$, maka dapat diartikan bahwa terdapat pengaruh yang signifikan antara Pesan Iklan "Dana App - Dompet Digital Indonesia 60s (2018)" terhadap Keputusan Penggunaan Aplikasi Dana.

Kata Kunci: iklan televisi, penggunaan aplikasi dana, pesan iklan

\section{Pendahuluan}

Komunikasi memiliki peranan penting di dalam kehidupan manusia. Dalam prosesnya, komunikasi memiliki dua tahap, yaitu proses komunikasi secara primer dan sekunder (Effendy, 2011). Berkomunikasi dapat dilakukan berbagai cara, salah satunya yaitu menggunakan media massa. Media massa yang paling sering digunakan yaitu media massa internet. Melalui internet dapat terhubung dengan semua orang di berbagai belahan dunia. Meski demikian internet juga memiliki keterbatasan, salah satunya adalah fasilitas internet hanya dapat diakses dengan menggunakan perangkat modern seperti smartphone, komputer, laptop dan lainnya. Oleh karena itu salah satu alternatif media yang masih aktif dan mudah untuk digunakan adalah Televisi. Televisi merupakan media massa yang mengalami perkembangan paling fenomenal di dunia (Badjuri, 2010). Selain memberikan beberapa fungsi, televisi juga menyediakan iklan di dalamnya. Menurut Widya ( dalam Kotler \& Amstrong, 1997) Untuk menghasilkan iklan yang baik selain memperhatikan pesan iklan diperlukan juga rumus iklan yaitu adalah AIDDA. Menurut Diah Ayu Candraningrum dalam jurnalnya mengungkapkan Iklan kreatif berarti iklan yang tidak biasa pada umumnya, berbeda, dan unik dibanding iklan lainnya. Jika sebuah iklan sudah memiliki kualitas pesan dan memiliki isi atau ilustrasi yang kreatif, akan membuat iklan tersebut memiliki daya tarik yang lebih di mata masyarakat (dalam Viviana dan Candraningrum, 2018). Teknologi menjadi latar belakang terbentuknya aplikasi digital modern yang canggih, salah satunya yaitu aplikasi dompet digital. Oleh karena itu, banyak brand atau aplikasi dompet digital lain yang terbentuk salah satunya yaitu Aplikasi Dana. Penulis memilih aplikasi Dana menjadi topik iklan televisi dalam penelitian ini karena memiliki beberapa kelebihan, salah satunya yaitu berdasarkan peringkat, "DANA sebagai pendatang baru aplikasi $e$-wallet di Indonesia langsung menunjukkan kegigihannya untuk menjadi pioner aplikasi $e$-wallet di Indonesia. Berdasar data riset iPrice Group, DANA memiliki pengguna aktif bulanan yang relatif stabil sejak Q2 2018 hingga Q2 2019. Dana berhasil naik satu peringkat di kuartal 2 2019 menggantikan LinkAja di posisi ketiga," ujar riset iPrice dan App Annie, seperti dikutip CNBC Indonesia (https://www.cnbcindonesia.com/tech/20190815104730-3792151/daftar-10-dompet-digital-terpopuler-di-ri-siapa-jawaranya) diakses pada 15 agustus 2019 pada pukul 11:27. Strategi promosi melalui iklan yang dilakukan oleh aplikasi dana sangat menarik. Iklan televisi tersebut berjudul "Dana App - Dompet Digital Indonesia 60s (2018)" (https://www.youtube.com/watch? $\mathrm{v}=\mathrm{zg} 391 \mathrm{bF} 3 \mathrm{biA}$ ) diakses pada 17 november 2018. Sehingga penulis ingin menulis dan meneliti dengan judul "Pengaruh Pesan Iklan Televisi "Dana App - Dompet Digital Indonesia 60s (2018)" Terhadap Keputusan Penggunaan Aplikasi Dana.

Hipotesis dalam penelitian ini adalah:

$\mathrm{H}_{0}$ : Tidak terdapat pengaruh antara Pesan Iklan "Dana App - Dompet Digital Indonesia 60s (2018)" terhadap Keputusan Penggunaan Aplikasi Dana.

Ha: Terdapat pengaruh antara Pesan Iklan "Dana App - Dompet Digital Indonesia 60s (2018)" terhadap Keputusan Penggunaan Aplikasi Dana. 


\section{Metode Penelitian}

Jenis penelitian yang digunakan dalam skripsi ini yaitu penelitian kuantitatif dengan menggunakan penelitian survey. Metode survey adalah metode riset dengan menggunakan kuesioner sebagai instrumen pengumpulan datanya, dengan tujuan untuk memperoleh informasi dari sejumlah responden yang dianggap mewakili sejumlah populasi tertentu (Kriyantono, 2007)

Populasi didalam penelitian ini yaitu generasi milenial di wilayah DKI Jakarta. Sedangkan sampel dalam penelitian ini ialah pria atau wanita berjumlah 100 responden,yang merupakan generasi milenial di DKI Jakarta, yang berumur antara 1837 tahun, dan pernah menonton iklan televisi "Dana App - Dompet Digital Indonesia 60s (2018)". Teknik dalam pengambilan sampel penelitian ini yaitu non probability sampling. Metode yang digunakan adalah purposive sampling, peneliti secara sengaja memilih anggota sampel dengan kriteria tertentu yang dianggap dapat memberikan informasi yang diperlukan. Pengumpulan data pada penelitian ini berupa penyebaran kuesioner berskala Likert. Data primer dalam penelitian ini dengan menggunakan kuesioner, sedangkan data sekunder dalam penelitian ini adalah mendapat data dari berbagai jurnal yang relevan dengan penelitian dan juga dari internet. Untuk mengetahui keabsahan data dalam penelitian ini, penulis menggunakan Uji Validitas, Uji Reliabilitas, dan Uji Normalitas. Kemudian dalam pengolahan dan analisis data, penulis menggunakan Uji Analisis Linier Sederhana, Uji Koefisien Korelasi, Uji Koefisien Determinasi $\left(\mathrm{R}^{2}\right)$, dan Uji T (T-Test).

Tabel 1: Operasional Variabel

\begin{tabular}{|c|c|c|c|}
\hline Variabel & Dimensi & Indikator & Skala \\
\hline \multirow[t]{3}{*}{$\begin{array}{l}\text { Pesan Iklan Aplikasi } \\
\text { "DANA" } \\
\text { (Variabel X) }\end{array}$} & 1. Isi pesan & $\begin{array}{l}\text { 1. Pesan iklan televisi } \\
\text { "Dana App - Dompet } \\
\text { Digital Indonesia 60s } \\
\text { (2018)" mudah } \\
\text { dimengerti. } \\
\text { 2. Pesan iklan televisi } \\
\text { "Dana App - Dompet } \\
\text { Digital Indonesia 60s } \\
\text { (2018)" mudah diingat. }\end{array}$ & Likert \\
\hline & 2. Struktur pesan & $\begin{array}{l}\text { 3. Struktur pengucapan } \\
\text { kata-kata pada iklan } \\
\text { televisi "Dana App - } \\
\text { Dompet Digital } \\
\text { Indonesia 60s (2018)" } \\
\text { mudah dimengerti. } \\
\text { 4. Alur Pesan iklan } \\
\text { televisi "Dana App - } \\
\text { Dompet Digital } \\
\text { Indonesia 60s (2018)" } \\
\text { membangun kesan } \\
\text { positif terhadap aplikasi } \\
\text { DANA. }\end{array}$ & Likert \\
\hline & 3. Format pesan & $\begin{array}{l}\text { 5. Adegan cerita di } \\
\text { dalam iklan televisi } \\
\text { "Dana App - Dompet } \\
\text { Digital Indonesia 60s }\end{array}$ & Likert \\
\hline
\end{tabular}




\begin{tabular}{|c|c|c|c|}
\hline & & $\begin{array}{l}\text { (2018)" sesuai dengan } \\
\text { karakteristik dari } \\
\text { keunggulan aplikasi } \\
\text { DANA } \\
\text { 6. Musik latar di dalam } \\
\text { iklan televisi "Dana App } \\
\text { - Dompet Digital } \\
\text { Indonesia 60s (2018)" } \\
\text { mendukung } \\
\text { penyampaian pesan } \\
\text { iklan. }\end{array}$ & \\
\hline & 4. Sumber pesan & $\begin{array}{l}\text { 7. Pemeran di dalam } \\
\text { iklan televisi "Dana App } \\
\text { - Dompet Digital } \\
\text { Indonesia 60s (2018)" } \\
\text { menunjukan gerak-gerik } \\
\text { dan ekspresi wajah yang } \\
\text { dapat dimengerti. } \\
\text { 8. Pemeran di dalam } \\
\text { iklan televisi "Dana App } \\
\text { - Dompet Digital } \\
\text { Indonesia 60s (2018)" } \\
\text { menunjukan kelebihan } \\
\text { dari aplikasi DANA. }\end{array}$ & Likert \\
\hline \multirow[t]{4}{*}{$\begin{array}{l}\text { Keputusan Penggunaan } \\
\text { Aplikasi DANA (variabel } \\
\text { Y) }\end{array}$} & $\begin{array}{l}\text { 1. Attention } \\
\text { (perhatian) }\end{array}$ & $\begin{array}{l}\text { 9. Khalayak } \\
\text { memperhatikan pesan } \\
\text { iklan dari iklan televisi } \\
\text { "Dana App - Dompet } \\
\text { Digital Indonesia 60s } \\
\text { (2018)" } \\
\text { 10. Khalayak } \\
\text { memperhatikan fitur } \\
\text { yang ditampilkan dalam } \\
\text { iklan televisi "Dana App } \\
\text { - Dompet Digital } \\
\text { Indonesia 60s (2018)". }\end{array}$ & Likert \\
\hline & 2. Interest (minat) & $\begin{array}{l}\text { 11. Khalayak tertarik } \\
\text { pada pesan iklan dalam } \\
\text { iklan televisi "Dana App } \\
\text { - Dompet Digital } \\
\text { Indonesia 60s (2018)" } \\
\text { 12. Khalayak tertarik } \\
\text { pada fitur yang diberikan } \\
\text { aplikasi DANA. }\end{array}$ & Likert \\
\hline & 3. Desire (hasrat) & $\begin{array}{l}\text { 13. Khalayak ingin } \\
\text { mencoba menggunakan } \\
\text { aplikasi DANA } \\
\text { 14. Khalayak ingin } \\
\text { mencoba menggunakan } \\
\text { fitur yang diberikan } \\
\text { aplikasi DANA. }\end{array}$ & Likert \\
\hline & $\begin{array}{ll}\text { 4. } & \text { Decision } \\
\text { (keputusan) }\end{array}$ & $\begin{array}{l}\text { 15. Khalayak } \\
\text { memutuskan untuk }\end{array}$ & Likert \\
\hline
\end{tabular}




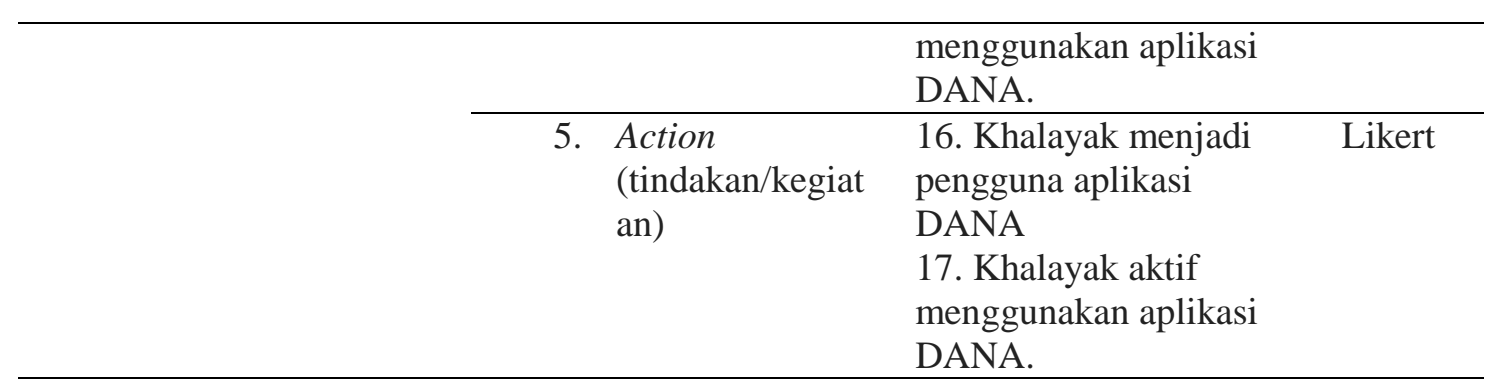

\section{Hasil Temuan dan Diskusi.}

Uji Validitas

Tabel 2. Hasil Analisis Validitas

\begin{tabular}{|c|c|c|c|}
\hline \multirow{8}{*}{$\begin{array}{l}\text { Pesan Iklan Dana } \\
\text { (Variabel X) }\end{array}$} & Indikator 1 & 0.677 & Valid \\
\hline & Indikator 2 & 0.555 & Valid \\
\hline & Indikator 3 & 0.575 & Valid \\
\hline & Indikator 4 & 0.552 & Valid \\
\hline & Indikator 5 & 0.495 & Valid \\
\hline & Indikator 6 & 0.602 & Valid \\
\hline & Indikator 7 & 0.569 & Valid \\
\hline & Indikator 8 & 0.380 & Valid \\
\hline \multirow{9}{*}{$\begin{array}{l}\text { Keputusan Penggunaan Aplikasi } \\
\text { DANA (Variabel Y) }\end{array}$} & Indikator 9 & 0.385 & Valid \\
\hline & Indikator 10 & 0.511 & Valid \\
\hline & Indikator 11 & 0.660 & Valid \\
\hline & Indikator 12 & 0.753 & Valid \\
\hline & Indikator 13 & 0.695 & Valid \\
\hline & Indikator 14 & 0.747 & Valid \\
\hline & Indikator 15 & 0.716 & Valid \\
\hline & Indikator 16 & 0.749 & Valid \\
\hline & Indikator 17 & 0.831 & Valid \\
\hline
\end{tabular}

Berdasarkan Tabel diatas, hasil Uji Validitas menunjukan setiap pernyataan dari variabel $\mathrm{X}$ dan $\mathrm{Y}$ dinyatakan valid, karena nilai dari corrected item total correlation lebih besar dari patokannya yaitu 0.2

\section{Uji Reliabilitas}

Hasil dari Uji Reliabilitas Variabel X dengan menggunakan SPSS ver.20 menunjukkan bahwa 8 butir pertanyaan variabel X (Pesan Iklan Aplikasi Dana) memiliki nilai Cronbach's Alpha sebesar 0.667 yang artinya Pesan Iklan Aplikasi Dana memiliki instrumen yang reliabel karena nilai Cronbach's Alpha >0,6.

Hasil dari Uji Reliabilitas Variabel Y dengan menggunakan SPSS ver.20 menunjukkan bahwa 9 butir pertanyaan variabel Y (Keputusan Penggunaan Aplikasi Dana) memiliki nilai Cronbach's Alpha sebesar 0.839 yang artinya Keputusan Penggunaan Aplikasi Dana memiliki instrumen yang reliabel karena nilai Cronbach's Alpha >0,6. 


\section{Uji Normalitas}

Hasil Uji Normalitas penelitian ini menunjukkan nilai signifikan sebesar 0.156, karena hasil signifikan > dari 0.05 maka penelitian ini ter distribusi normal. Setelah melakukan Uji Validitas, Uji Reliabilitas, dan Uji Normalitas dilakukan dan dinyatakan valid, reliabel, dan normal, maka semua pertanyaan tersebut dinyatakan layak untuk disebarkan kepada jumlah responden yang telah ditentukan yaitu pria atau wanita sebanyak 100 responden, yang merupakan generasi milenial di DKI Jakarta, yang berumur antara 18-37 tahun, dan pernah menonton iklan televisi "Dana App Dompet Digital Indonesia 60s (2018)".

\section{Uji Analisis Linier Sederhana}

Rumus persamaan regresi linier berganda pada penelitian ini ialah:

$$
\mathrm{Y}=8.188+0.885 \mathrm{X}
$$

Maka dapat disimpulkan sebagai berikut :

a. Kostanta $(\propto)$ bernilai positif yaitu sebesar 8.188 artinya jika variabel - variabel bebas yaitu X (Pesan Iklan Dana) bernilai 0 maka variabel dependen Y (Keputusan Penggunaan Aplikasi Dana) naik sebesar 8.188 satuan.

b. Variabel bebas X (Pesan Iklan Dana) bernilai positif yaitu sebesar 0.885 hal ini menunjukkan adanya hubungan yang searah. Artinya setiap. peningkatan sebesar 1 satuan variabel X (Pesan Iklan Dana) maka Penggunaan Aplikasi Dana 0.885 satuan.

\section{Uji Koefisien Korelasi}

Diketahui bahwa Hasil Uji Koefisien Korelasi (R) dari variabel X (Pesan Iklan aplikasi Dana) terhadap variabel Y (Keputusan Penggunaan Aplikasi Dana) dalam penelitian ini sebesar 0.551, karena hasil Uji Koefisien Korelasi berada di rentang 0,40 - 0,599 maka dapat disimpulkan bahwa antara Pesan Iklan Aplikasi Dana terhadap Keputusan Penggunaan Aplikasi Dana terdapat hubungan dan sifat hubungan tersebut adalah sedang.

\section{Uji Koefisien Determinasi $\left(\mathbf{R}^{2}\right)$}

Hasil koefisien determinasi diketahui dengan melihat angka pada R Square. Hasil dari R Square adalah 0.30, hal ini dapat dikatakan kemampuan variabel variabel independen (Pesan Iklan Aplikasi Dana) dalam mempengaruhi variabel dependen (Keputusan Penggunaan Aplikasi Dana). Karena berdasarkan hasil uji determinasi pengaruh X (Pesan Iklan Aplikasi Dana) yang peneliti teliti terhadap Y (Keputusan Penggunaan Aplikasi Dana) yang peneliti amati nilainya sebesar 0.303 $(30,3 \%)$ lalu sisanya $0.697(69,7 \%)$ Y dipengaruhi oleh faktor lain yang peneliti tidak teliti.

\section{Uji T (T-Test)}

Hasil Uji T pada variabel $\mathrm{X}$ adalah $\mathrm{H}_{\mathrm{o}}$ ditolak dan Ha diterima, yang berarti terdapat pengaruh Pesan Iklan Aplikasi Dana terhadap Keputusan Penggunaan Aplikasi Dana. Nilai sig $<\alpha$ yaitu $0,000<0,05$, maka dapat diartikan bahwa terdapat pengaruh yang signifikan antara Pesan Iklan "Dana App - Dompet Digital Indonesia 60s (2018)" terhadap Keputusan Penggunaan Aplikasi Dana. 


\section{Simpulan}

Berdasarkan hasil penelitian dan pembahasan yang telah dilakukan oleh peneliti, maka peneliti menarik kesimpulan bahwa Pesan Iklan Aplikasi Dana dapat berpengaruh dengan Keputusan Penggunaan Aplikasi Dana. Jadi, semakin tinggi Isi Pesan dalam Pesan Iklan Aplikasi Dana maka semakin tinggi pula Keputusan Penggunaan Aplikasi Dana nya. Lalu, Keputusan Penggunaan Aplikasi Dana dipengaruhi oleh Action (tindakan/kegiatan) yaitu Khalayak aktif menggunakan aplikasi Dana. Keputusan Penggunaan Aplikasi Dana ditandai keinginan untuk aktif menggunakan aplikasi dana, dikarenakan hal tersebut dapat menguntungkan pengguna untuk melakukan hal tersebut.

\section{Ucapan Terima Kasih}

Terima kasih penulis haturkan kepada Fakultas Ilmu Komunikasi Universitas Tarumanagara yang telah memberikan tugas untuk pembuatan Jurnal ini, serta Perusahaan Aplikasi Dana yang berperan menjadi judul penelitian ini. Ucapan terima kasih juga saya haturkan kepada orang tua, saudara, kerabat, dan responden yang telah memberikan dukungan dan bantuannya kepada penulis.

\section{Daftar Pustaka}

Badjuri Adi. (2010). Jurnalistik Televisi. Ed 1. Cet 1. Yogyakarta: Graha Ilmu Chintya Viviana, Diah Ayu Candraningrum (2018), E-Wom Oleh Kalangan Milenial Terhadap Akun @makansampaikenyang Sebagai Pemberi Rekomendasi Kuliner. Jurnal Prologia.; Vol 2, No 2

Effendy, Onong Uchjana. (2011). Ilmu Komunikasi: Teori dan Prakteknya, Bandung : Remaja Rosdakarya

Kotler, Philip and Gary Armstrong. (2012). Prinsip-prinsip Pemasaran. Edisi 13. Jilid 1. Jakarta: Erlangga.

Kriyantono, Rachmat. (2007). Teknik Praktis Riset Komunikasi. Jakarta: Kencana Prenada Media Group.

Widya Atidhira Hutabarat, Toni Wijaya (2017), pengaruh pesan iklan line versi film "ada apa dengan cinta" mini drama terhadap penggunaan fitur find alumni drama terhadap penggunaan fitur find alumni di kota Bandar Lampung. Jurnal Kajian Komunikasi Tahun 2017; Vol 1, Nomor.1 